\title{
Teachers' Perceptions of Learning Technologies: An Informing Issue in High School Education.
}

\author{
Chris Cope \\ La Trobe University, Australia \\ C.Cope@tatrobe.edturat
}

\author{
Peter Ward \\ Euroa Secondary College, Australia
}

\begin{abstract}
A study of the perceptions of learning technologies of a group of high school teachers was undertaken. Underlying the study was the research-based notion that enhanced learning outcomes are likely only if learning technologies are perceived as a means for students to seek the meaning of the subject material. The teachers were interviewed about their perceptions at the beginning and end of a two year period. The interview transcripts were analyzed using phenomenographic research approaches to identify critical variation in perception. The teachers' perceptions of learning technologies were found to have unrelated "what" and "how" components. The "what" component concerned perception of technology. The "how" component concerned perception of the nature of enhanced learning. The various perceptions were found to be inadequate with regard to the "how" component and unlikely to lead to enhanced student learning outcomes. The research findings lead to the suggestion that the teachers need professional development in the nature of enhanced learning and how learning technologies can be used in the classroom to facilitate better learning outcomes.
\end{abstract}

Keywords: Learning technologies, phenomenographic research, teaching and learning approaches.

\section{Introduction}

Learning technologies are being widely promoted and supported as a means of better informing high school students. The Department of Education (DoE), in Victoria, Australia is an example. In a number of promotional publications the DoE proposes that learning technologies, when used appropriately, have the potential to lead to enhanced student learning.

Learning technologies are the various forms of information technology that are used to enhance student learning. They represent the incorporation of information technology (including both computer and communications technology) into teaching and learning. It has been shown that learning technologies, integrated into the learning environment, can significantly enhance learning outcomes in the classroom, motivating and stimulating learning and providing new learning opportunities (DoE, 1998, p.14).

Material published as part of this proceedings, either on-line or in print, is copyrighted by the author with permission granted to the publisher of Informing Science for this printing. Permission to make digital or paper copy of part or all of these works for personal or classroom use is granted without fee provided that the copies are not made or distributed for profit or commercial advantage AND that copies 1) bear this notice in full and 2) give the full citation on the first page. It is permissible to abstract these works so long as credit is given. To copy in all other cases or to republish or to post on a server or to redistribute to lists requires specific permission from the author.
Given the amount of promotion and support, it is a concern that research into the impact of learning technologies on students' learning outcomes is limited according to Mitchell and Bluer (1997). One of the difficulties is being able to define and measure enhanced learning outcomes attributable to the use of learning technologies. Methods of overcoming and/or avoiding this difficulty have varied. Jones et al. (1996), for instance, looked for a set of classroom variables associated with the use of learning technologies that were indicative of effective teaching and learning.

Our research project took a different tack. The research investigated high school teachers' perceptions of learning technologies. Underpinning the research was a notion we have developed from published research into student learning. Unless teachers hold appropriate perceptions of learning technologies, enhanced student learning outcomes are unlikely. We will develop and justify this notion later in the paper.

Specifically our research investigated the perceptions of learning technologies of a group of high school teachers at Euroa Secondary College (ESC) in Victoria, Australia. The research questions were:

1. How did the group of teachers perceive learning technologies? 


\section{Chris Cope and Peter Ward}

2. Did the teachers' perceptions of learning technologies change over a two year period?

The significance of our research lies in two areas:

1. A review of the literature indicated that high school teachers' perceptions of learning technologies have not been studied extensively.

2. If teachers' perceptions were found to be inappropriate then a path of corrective action is apparent. Support for the use of learning technologies in classrooms needs to be directed toward improving the initial education and later professional development of teachers.

The generalizability of the findings of our research is left to the reader. To assist, the paper includes details of the high school and group of teachers who participated in the research.

\section{Theoretical framework}

The decision to investigate teachers' perceptions of learning technologies was based on the findings of a body of recent published research into teachers' and students' perceptions of natural teaching and learning contexts (see Marton \& Booth, 1997; Prosser \& Trigwell, 1999 for overviews). The data for this body of research was obtained mainly from interviews with teachers and students about their own teaching and learning experiences. The data was analyzed using phenomenographic research approaches. These approaches are qualitative and seek to describe variation in groups of individuals' experiences of phenomena in the world (Marton, 1981). A summary of the some of the findings of phenomenographic research into students' and teachers' perceptions of their own learning situations is presented next. An understanding of these findings is an important background to the research reported in this report. The findings are summarized diagrammatically in Figure 1, and then described.

Teachers have been found to approach teaching in a limited number of qualitatively different ways, which are related to the qualitatively different ways teachers conceptualize teaching and learning (Prosser \& Trigwell, 1999). Broadly, teachers that perceive learning as the accumulation of information, view teaching as the transfer of information, and use a teacher centered approach where the teacher imparts information to the students. In contrast, teachers who view learning as conceptual change, view teaching as facilitating conceptual change, and use a student centered teaching approach where the students have more responsibility for their own learning.

The way a teacher approaches teaching has been found to influence the way students approach learning (Trigwell, Prosser \& Lyons, 1999). A conceptual change/student focussed teaching approach has been found to encourage deep learning approaches in students. Deep learning approaches have an intention to seek meaning in learning situations through linking aspects of the content. With a deep learning approach there is the possibility of conceptual change. In contrast, an information transfer/teacher centered teaching approach has been found to encourage surface learning approaches. Surface learning approaches focus on aspects of the content in isolation with the intention of recalling the content in assessment situations. There is no intention to seek the meaning in the content and hence, little likelihood of conceptual change (Ramsden,

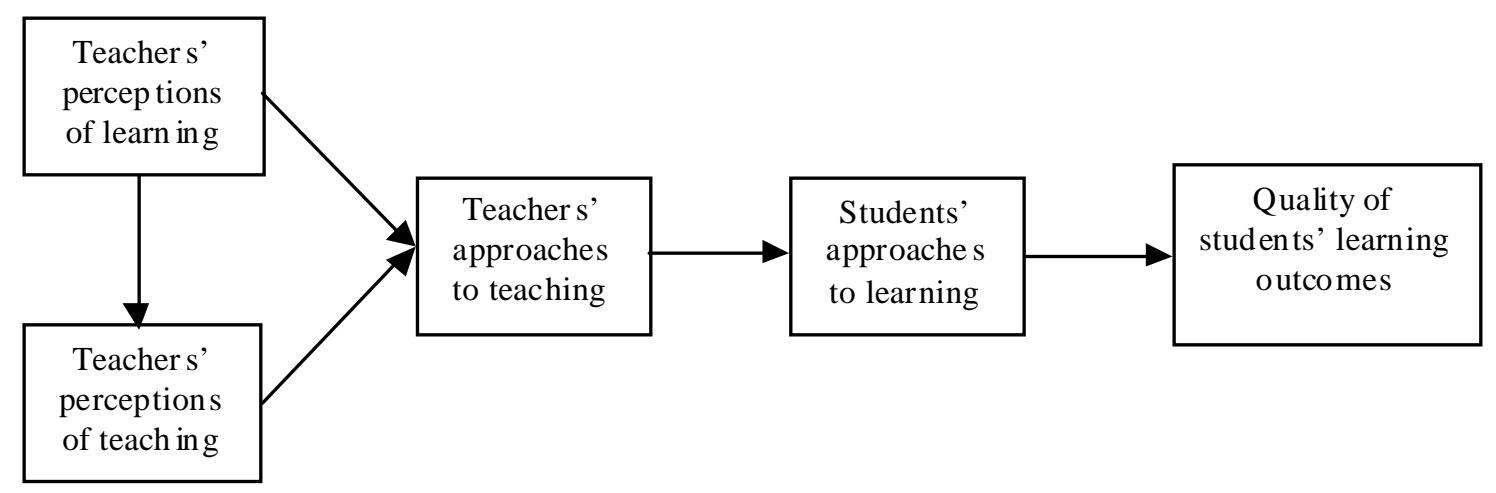

Figure 1: Empirically identified relations between teachers' perceptions and the quality of students' learning outcomes. 


\section{Teachers' perceptions of learning technologies}

1988). It is assumed in this paper that conceptual change leading to deeper understanding represents an enhanced learning outcome in comparison to the ability to recall isolated aspects of content.

A major contention underlying our research project was developed from the theoretical framework just outlined. As there is a learning aspect to learning technologies and an empirically identified link between teachers' perceptions of learning and the quality of students' learning outcomes, we contend that teachers' perceptions of learning technologies will influence whether enhanced student learning outcomes are likely. Logically it follows that unless a teacher uses learning technologies as part of a studentcentered/conceptual change teaching approach and, consequently, students use learning technologies as part of a deep learning approach, enhanced learning outcomes are highly unlikely. Teachers need to perceive learning technologies as tools which can be used by students to seek meaning in the content being studied through interrelating the various aspects of the content, looking for an understanding (a deep learning approach). Using learning technologies as a means to source and commit to memory a broader range of information more quickly (a surface learning approach) is not enough to enhance learning. Thus, a research focus on teachers' perceptions of learning technologies was taken as, without appropriate teacher perceptions, deep learning approaches and enhanced student learning outcomes are unlikely.

\section{Method}

To investigate high school teachers' perceptions of learning technologies a two-year, longitudinal study of a group of teachers at Euroa Secondary College (ESC), Victoria, Australia was implemented. ESC is a small rural high school offering a broad curriculum to 320 students (12-18 year olds) on a single campus. Like many Victorian high schools, ESC introduced computer technology into the curriculum in the mid 1980s and learning technologies have been introduced into all key learning areas since then. During the research period $(1997-1999)$ two intensive professional development programs were run. More than $90 \%$ of the teachers participating in the research project successfully completed the Learning With the Internet (12 hours) and Computers Across the High school Curriculum (8 hours) programs. Also during the research period most of the teachers studied received laptops as part of a DoE initiative.
Teachers' perceptions of learning technologies were investigated by analyzing the transcripts obtained from 31 indepth, semi-structured interviews with a group of 15 teachers from ESC who volunteered to be part of the research. The average age of the teachers was 39 years. A series of guide questions (Appendix 1) that provided an impetus for teachers to reflect on their perceptions of learning technologies were designed, piloted and refined. Two pilot interviews were held; 15 teachers were interviewed at the beginning of the research period; and 14 of the same teachers at the end. Teachers' responses to the guide questions were probed during the interviews until an understanding was achieved between the interviewer and the teacher whereupon the next guide question was introduced. The interviews were recorded and transcribed. The combined beginning and end transcripts were analyzed using a phenomenographic research approach as described by Marton (1986). This approach sought to analyze the distinctly different perceptions of learning technologies evident in the interview transcripts, and to identify the relationships between the different perceptions. Analysis was an iterative process of considering and comparing statements in the transcripts many times to get a feel for the different perceptions of learning technologies underlying the teachers' statements. For a detailed discussion of a phenomenographic analysis similar in method to the one used in this study see Cope (2000).

To further investigate any relationship between the perceptions that were identified, each interview transcript was classified against the different perceptions identified in the phenomenographic analysis. The classification process involved determining the perception of learning technologies that underlay the statements on each interview transcript. The classifications were then analyzed qualitatively and quantitatively to give further insight into the nature of the perceptions and to investigate change in perception of learning technologies over the research period.

The classification process was also an important part of establishing the validity and reliability of the findings. Justification of validity in phenomenographic research lies in a full and open account of a study's method and results. The judgement of credibility and trustworthiness then lies with the person reading the study (Booth, 1992). Reliability is not considered a valid measure of phenomenographic research, rather the communicability of the perceptions identified by the researcher needs to be established (Cope, 2000). Judgement of reliability is not appropriate because no two researchers can be expected to identify the same perceptions underlying a set of interview transcripts. While 


\section{Chris Cope and Peter Ward}

there are some calls for researchers to suppress their prior knowledge in phenomenographic research, in practice this is not possible. Different researchers will bring different sets of prior knowledge to the research process. The perceptions that form the findings of the research are, therefore, a relation between an individual researcher and the data. What is important, however, is that the findings are described and illustrated in a manner that communicates to other researchers the critical differences between the perceptions. Given a description of the perceptions and the interview transcripts, other researchers should be able to see the different perceptions in the data. For this reason, the perceptions of learning technologies that we identified are described in detail in the next section and the text files containing the interview transcripts are available for anonymous ftp from iron-

bark.bendigo.latrobe.edu/usr/ftp/pub/cope/learntech.

\section{Results}

The research findings are presented in two sub-sections corresponding to the two research questions outlined earlier in the paper.

\section{How did the group of teachers perceive learning technologies?}

A number of distinctly different perceptions of learning technologies were identified. Each perception consisted of a "what" and a "how" component. The "what" component concerned the technology aspect of learning technology what constituted a technology. The "how" component related to the nature of the impact of the technology on students' learning. Variation was found in both the "what" and "how" components. The variation in the "what" component is now described and illustrated with quotes from the data.

Perception W1: Anything which can be physically manipulated by the learner

In this perception, technology is considered as anything with which students interact physically in the learning process. A technology can vary from a pencil and paper or a lump of clay to something electronic like a computer.

When learning to draw an object, a pencil and paper are normally used. Would you consider the pencil and paper to be a learning technology?

Yes.

What makes it a learning technology?
The fact that a human being, the pencil and the paper can combine to produce a drawing. It is a physical process conjured up and manipulated by human beings to record or communicate. Can you think of a teaching aid that you would not call a learning technology?

There are very few things that aren't used in a physical way that if you use them to learn you learn from.

\section{Perception W2: Any mechanical or technical equipment}

This perception does not incorporate objects which are strictly manual rather than technical or mechanical. For instance textiles or clay would not be considered as learning technologies. All other mechanical and technical aids to learning are incorporated.

\section{What makes a pencil and paper a learning technology? They are a tool operated by a human. \\ Can you think of a teaching aid that you would not call a learn- ing technology? \\ A person, because they are not mechanical.}

Perception W3: A progressive piece of mechanical or technical equipment

The nature of the mechanical or technical equipment is important here. The equipment has to demonstrate some development over and above an older piece of equipment.

Can you give me an example of a learning technology? Computers.

What makes them learning technologies?

The fact that it is a technological piece of equipment and progressive as opposed to something that was done by hand in the past.

\section{Perception W4: Computer related equipment}

In this perception technology is restricted to something electronic.

What do the words "learning technologies" mean to you? Well I think it is something which enhances students' learning and requires something to be plugged into the wall.

The different perceptions of the "what" component of learning technologies form a hierarchy based on logical inclusiveness. Perception W1: Anything which can be physically manipulated by the learner includes the three other perceptions and represents a broad view of the technology component of learning technologies. Perception W4: Computer related equipment, in contrast, is a narrower view of the technology component of learning technologies. Perception W4: Computer related equipment is consistent with the definition of learning technologies provided by the DoE and given earlier in the report. 


\section{Teachers' perceptions of learning technologies}

The variation in the "how" component of the perceptions of learning technologies is now described and illustrated with quotes from the data.

Perception H1: Enhances learning (higher quality outcomes)

In this perception the use of learning technologies in the classroom by students leads to learning outcomes that involve understanding - the grasping of the meaning in the subject matter.

If two students of equal ability completed a work requirement and one used learning technologies and one didn't, how would you expect the one who used the learning technologies to use them in their work requirement?

...Alright then if they were using the new technologies then the presentation might be more glamorous and also they might have access to information that they might not have otherwise had and also sometimes when they are using things like computer graphics to present something it helps them to understand it more quickly or more visually, or they grasp it and therefore they can explain it in their answer more clearly because they have understood.

Perception H2: Encourages the development of better learning techniques and strategies

Deep learning approaches with the possibility of enhanced learning outcomes require particular learning techniques and strategies. In this perception learning technologies are seen to enable students to develop these techniques and strategies.

What do the words "learning technologies" mean to you? They would be pieces of technology, instruments, machines which enable students to enhance and develop their learning techniques, learning strategies.

Do you think the World Wide Web is a learning technology? Without a doubt.

Why?

Because it is making use of facilities that go beyond the immediate human body in terms of being able to resource information, to resource a whole lot of aspects of learning that can't take place without it, it enhances the learning process.

Perception H3: Development of skill with or knowledge about the technology

In this perception learning is enhanced because in addition to learning about the content, skills in using the technology are learnt.

What do you think the Department of Education means by enhanced learning?
I would imagine that they mean it broadens learning in a particular area so they can take in what is available in the modern day and learn how to use the equipment.

Is this the same as what you think enhanced learning is? Well I think that learning now encompasses the use of modern devices. You have to prepare kids for the modern world. I don't consider that we necessarily couldn't get most of the ideas and basic understanding across without these technologies in most areas.

\section{Perception H4: Aids/Assists}

Two different senses of aiding and assisting learning were evident in this perception. Firstly, the technology makes the teaching and learning easier through better access to more information. Secondly the technology assists learning through motivating the students and making the learning process more enjoyable.

What makes your example a learning technology?

Simply because it is a tool that is a development or enhancement and that has become available recently. It is something which enables kids to do their work more easily and allows you to teach them more easily. It makes my job easier.

What impact would your example (digital camera) have on your students' learning?

It would have a very large impact, it can make it relevant to the kids, keeping them involved in all the facets of the process of designing a product and making it, they don't have to rely on someone else to take the image.

What about a normal camera?

Yes it's a learning technology. It will assist kids with their learning.

Are there any differences in the learning?

A digital camera is much more immediate and the kids are involved in the whole process much more easily and they can see the image, the immediacy is a big advantage. The big advantage with many learning technologies is the more technical it becomes its much more immediate, which kids really appreciate and respond to.

Perception H5: Quicker, better presentation of more up-todate, expansive information

The focus here is on enhanced learning involving better presentation of the material to be handed in.

If two students of equal ability completed a work requirement and one used learning technologies and one didn't, what differences would you expect to see in the work requirement? I think you would see it in the end product in terms of it being printed out and typed up, but I wouldn't expect to see more or better information.

The different "how" components of the perceptions of learning technologies form a hierarchy based on logical 


\section{Chris Cope and Peter Ward}

inclusiveness. Perception H1: Enhances learning is inclusive of all the other perceptions. Enhanced learning outcomes resulting from the use of learning technologies require better learning techniques and strategies; skill in using the technology; assistance from the technology; and more effective presentation of the learning outcomes. The quote used to illustrate Perception $\mathrm{H} 1$ is also illustrative of the inclusive nature of the different perceptions.

The various "what" and "how" perceptions of learning technologies were combined in various ways in the interview transcripts. The combinations are illustrated in Table 1 in the classifications of the interview transcripts against the hierarchy of "what" and "how" components. Table 1, for instance, shows that 2 transcripts from the beginning interviews and 3 from the end interviews were classified as representative of anything electronic that enhanced students' skills in using technology (column W4, row H3).

Table 1 was used as the basis for a quantitative analysis of the relationship between the "what" and "how" components of the perceptions of learning technologies. Exact statistical techniques (Babinec \& Mehta, 1999) were used to cater for the low counts. No statistically significant relationship was found for the data from the beginning of the research period (Kendall's tau-c $=-.067, \mathrm{p}=.796$ ). There is a stronger association between the "what" and "how" components at the end of the research period but the association is not statistically significant (Kendall's tau-c = $.286, \mathrm{p}=.214)$.

\section{Did the teachers' perceptions of learning technolo- gies change over a two year period?}

Change in perception of learning technologies over the research period was investigated quantitatively using the classification data in Table 1 . There was no statistically significant change in the "what" or the "how" components of the perceptions of learning technologies.

\section{Discussion}

The finding of components of learning technologies in which there was variation in perception that can be described in a hierarchy of logical inclusiveness is consistent

\begin{tabular}{|c|c|c|c|c|c|c|c|c|c|c|}
\hline \multirow{3}{*}{$\begin{array}{l}\text { "how" (learn- } \\
\text { ing) component }\end{array}$} & \multicolumn{10}{|c|}{ "what" (technology) component } \\
\hline & \multicolumn{2}{|c|}{ W1. Anything } & \multicolumn{2}{|c|}{$\begin{array}{l}\text { W2. Mechanical } \\
\text { or technical }\end{array}$} & \multicolumn{2}{|c|}{$\begin{array}{l}\text { W3. Progressive } \\
\text { mechanical or } \\
\text { technical }\end{array}$} & \multicolumn{2}{|c|}{ W4. Electronic } & \multicolumn{2}{|c|}{ Totals } \\
\hline & & & 1 & 1 & 1 & & 1 & 1 & 3 & 2 \\
\hline $\begin{array}{l}\mathrm{H} 2 \text {. Better } \\
\text { learning strate- } \\
\text { gies }\end{array}$ & & & & 1 & & & & 1 & 0 & 2 \\
\hline $\begin{array}{l}\text { H3. Skills with } \\
\text { technology }\end{array}$ & 1 & & 2 & 1 & 1 & 1 & 2 & 3 & 6 & 5 \\
\hline H4. Assists/aids & & 3 & & & & 1 & & 1 & 0 & 5 \\
\hline $\begin{array}{l}\text { H5. Quicker, } \\
\text { better presenta- } \\
\text { tion }\end{array}$ & 2 & & & & 2 & & 2 & & 6 & 0 \\
\hline Totals & 3 & 3 & 3 & 3 & 4 & 2 & 5 & 6 & & \\
\hline
\end{tabular}

Table 1: Classifications of interview transcripts against the hierarchies of the "what" and "how" components of learning technologies (the figure in italics represents the beginning interviews. non-italics the end interviews) 


\section{Teachers' perceptions of learning technologies}

with the findings of many phenomenographic studies into other phenomena (see Marton \& Booth, 1997, for an overview). The finding of no relationship between the "what" and "how" components of the teachers' perceptions is not consistent with the findings of other research. We will consider this lack of a relationship later in this section.

Broadly the research showed that the group of teachers held inadequate perceptions of learning technologies, in particular the "how" component. On the basis of the DoE definition of learning technologies and contemporary research-based knowledge about teaching and learning, Perception H4: Assist/aids learning and Perception H5: Quicker, better presentation of more up-to-date, expansive information represent an inadequate view of enhanced learning. Given that teachers' perceptions of learning have been related to the quality of students' learning outcomes, Perceptions $\mathrm{H} 4$ and $\mathrm{H} 5$ are unlikely to be associated with the use of learning technologies in learning situations in a manner which will encourage deep learning approaches and the possibility of conceptual change (enhanced learning outcomes). While Perceptions H2 and H3 ascribe some importance to the learning process, only Perception $\mathrm{H} 1$ reflects knowledge about deep learning approaches. Table 1 documents the small number of interview transcripts in which evidence of Perception $\mathrm{H} 1$ of the "how" component of learning technologies was found.

The lack of a relationship between the "what" and "how" components of learning technologies is disturbing. We believe that the number and variety of combinations of the "what" and "how" components identified in the interview transcripts may be indicative of disintegrated perceptions. Disintegrated perceptions were identified in research into students' perceptions of their own learning situations by Prosser, Hazel, Trigwell and Lyons (1996). Students with disintegrated perceptions viewed their learning situation as requiring both surface and deep approaches to learning. The outcome was an approach to learning that resulted in learning outcomes significantly worse than those of students who adopted a surface learning approach. Teachers with disintegrated perceptions of learning technologies are unlikely to use learning technologies in a consistent manner in the classroom and highly unlikely to use them in a manner which will lead to enhanced student learning outcomes.

The lack of change in perception of learning technologies over the research period was also unexpected. The professional development programs and promotion of and support for learning technologies appear not have had a significant influence on teachers. While support and professional development focussed on the "what" component of learning technologies, our research demonstrates that the "how" component needs similar development.

We present the significance of our findings in the form of recommendations for four audiences:

\section{The ESC community}

The recommendation here is for teachers to undertake professional development in two areas.

a. Teachers at ESC need modern knowledge about student learning, in particular the nature of enhanced learning.

The understanding of enhanced learning displayed in the interview transcripts of the group of teachers at ESC was inadequate and unlikely to lead to the type of teaching approaches that encourage high quality learning outcomes. For instance in one interview transcript the following was written:

What about a photocopier, is it a learning technology? Well it does enhance learning, we don't have to use that bloody old fordiograph where you had to spend hours and hours preparing.

How does the photocopier enhance learning?

Well it enables you to give much better quality reproduction of things to kids. It gives you enlargements and it gets the job done more quickly which gives you time for other things.

Are you saying by speeding up the learning process you are going to enhance it?

No I am saying its speeding up our ability to get stuff to the kids. We are going to enhance their learning because we have more time for other things. We might put more time into their corrections.

The thrusts of this quote are common among the interview transcripts. Firstly, there is no evidence of enhanced learning meaning conceptual change. The teaching approach underpinning this quote is teacher centered/information transfer (its speeding up our ability to get stuff to the kids). Research has shown that this type of teaching approach is unlikely to encourage the deep learning approaches required for conceptual understanding (Trigwell, Prosser \& Lyons, 1999). Secondly, there is an emphasis throughout the quote on time, specifically not enough of it (it gets the job done more quickly which gives you time for other things). Student centered/conceptual development teaching approaches require time in development and in implementation. Students need time to look for the links between areas of content which comprise conceptual change and, 


\section{Chris Cope and Peter Ward}

hence, deeper understanding. Indeed one of the factors in a learning environment identified as encouraging surface learning approaches is the perception by students of a workload that is unmanageable (Ramsden, 1992). It is possible that a perception of an unmanageable workload by teachers is a factor encouraging a teachercentered/information transfer teaching approach.

b. Teachers at ESC need to contemplate, in a structured way, how learning technologies can be used to encourage deep learning approaches in students.

While the general nature of deep learning approaches and the teaching factors which encourage deep learning approaches are known, research findings show that the specific details of deep approaches to learning have been found to be discipline dependent (Ramsden, 1992; Gibbs, 1992). That is, a deep approach to learning about physics, for example, is different from a deep approach to learning about humanities or IT. Professional development is needed in which small groups of subject area teachers use their teaching experience and knowledge of learning technologies and enhanced learning to brainstorm ways in which the learning technologies can be used to encourage the factors which lead to deep learning approaches.

\section{Other high schools in Victoria}

The recommendation is for teachers at other schools to undertake similar professional development programs to those proposed for ESC. We believe the research results at ESC are generalisable to a majority of other Victorian high schools. The demands on high school teachers and the conditions of work are consistent across Victorian schools. On average, teachers at ESC are of similar age and experience to other high schools in the State and face similar challenges. There is no apparent reason why perceptions and use of learning technologies are not likely to be similar, unless particular schools have taken the necessary steps to focus on each teacher's perceptions of learning technologies and how the technologies can be employed to enhance learning in particular learning areas.

\section{The Department of Education}

While the DoE support for and publications about learning technologies are admirable endeavours, the findings of the research at ESC cast doubt on the likely success of the efforts to incorporate learning technologies across the curricula of Victorian high schools. Our research indicates that teachers are not likely to be perceiving learning tech- nologies and enhanced learning in a manner intended by the Department.

While it might be politically expedient to be seen to be promoting the use of learning technologies in schools, we believe the support to teachers has been misplaced in two areas:

1. The term "learning technologies" is a relatively new one and is at the forefront of promotion and support for enhanced learning in schools. Unfortunately professional development in the incorporation of learning technologies into the curriculum has focussed on teachers gaining skills in using the technologies. We recommend, on the basis of the findings of the research at ESC, that more DoE support is required for professional development programs that address teachers' perceptions of learning technologies, in particular the nature of enhanced learning and how learning technologies can be used in the classroom to enhance student learning.

2. Teachers need more time to integrate learning technologies into their curricula. In general, at ESC and other high schools in Victoria, teachers are facing an unmanageable workload. Under this pressure teachercentered/information transfer teaching approaches with a minimum of learning technology involvement are likely. As has been explained previously in the paper enhanced learning outcomes are unlikely under these teaching conditions and approaches. More time release needs to be made available to teachers in high schools to learn about learning technologies, enhanced learning and how learning technologies can be used to encourage enhanced learning outcomes.

\section{The "world" audience}

If the reader believes that the Victorian DoE initiatives in promoting and supporting learning technologies in high schools, the ESC context, and the characteristics of the group of teachers are similar to their own context then it may be appropriate to consider the recommendations we have made. More research from around the world concerning high school teachers' perceptions of learning technologies is needed to verify the generalisability of the results reported in our study. 


\section{Conclusion}

Learning technologies will never be the panacea to all teaching problems but when adequate skill in using the technologies is combined with a contemporary understanding of teaching and student learning they can be used to support teaching and learning approaches likely to encourage enhanced learning in students. Our research at ESC indicates that current DoE initiatives to introduce learning technologies into high school classrooms in Victoria are unlikely to have been generally and significantly successful at better informing students. In other high school contexts around the world where the controlling bodies have tried to introduce learning technologies in a similar manner, similar results can be expected.

Future success is only likely if more time release is made available to alter high school teachers' perceptions of learning technologies. Teachers need to engage in professional development programs concerning the nature of enhanced learning, skills in using learning technologies and how learning technologies can be used in the classroom to enhance student learning.

Research into the effect and impact of learning technologies on high school curricula needs to continue. To be of value the research needs to focus in a structured way on the chain of related factors known to lead to enhanced learning outcomes - teachers' perceptions of learning technologies, teachers' approaches to teaching, students approaches to learning and the quality of students' learning outcomes.

\section{References}

Babinec, T., \& Mehta, C. (1999). Exploring exact statistics. [On-line]. Available:

http://www.spss.com/newsltrs/kw/Kw58/StatSpeak.html.

Booth, S.A. (1992). Learning to program: A phenomenographic perspective. (Göteborg Studies in Educational Sciences, 89). Göteborg: Acta Universitatis Gothoburgensis.

Cope, C. (2000). Educationally critical aspects of the experience of learning about the concept of an information system. $\mathrm{PhD}$ thesis [On-line]. Available:

http://ironbark.bendigo.latrobe.edu.au/ cope/cope-thesis.pdf

DoE (Department of Education), (1998). Learning Technologies: Teacher Capabilities Guide. Melbourne, Vic.: Community Information Service.
Gibbs, G. (1992). Improving the Quality of Student Learning, Bristol: Technical and Educational Services.

Jones, B.F., Valdez, G., Nowakowski, J., \& Rasmussen, C. (1996). Plugging In : Choosing and Using Educational Technology (based on a report entitled Designing Learning and Technology for Educational Reform), Council for Educational Development and Research, North Central Regional Educational Laboratory. [Online]. Available: http://www.ncrel.org/sdrs/edtalk/toc.htm

Marton, F. (1981). Phenomenography - describing conceptions of the world around us. Instructional Science, 10, 177-200.

Marton, F. (1986). Phenomenography - a research approach to investigating different understandings of reality. Journal of Thought, 21 (3), 28-49.

Marton, F., \& Booth, S. (1997). Learning and Awareness, Mahwah, N.J.: Lawrence Erlbaum.

Mitchell, J., \& Bluer, R. (1997). A Planning Model for Innovation: New Learning Technologies. Report of the Office of Post Compulsory Education, Training and Employment: State Training Board of Victoria, Australia. [On-Line]. Available: http://www.otfe.vic.gov.au/planning/model/

Prosser, M., Hazel, E., Trigwell, K., \& Lyons, F. (1996). Qualitative and quantitative indicators of students' understanding of physics concepts, Research and Development in Higher Education, 19, 670676.

Prosser, M., \& Trigwell, K. (1999). Understanding learning and teaching: the experience in higher education. Philadelphia, PA: Society for Research into Higher Education \& Open University Press.

Ramsden, P. (1988). Studying learning: Improving teaching. In P. Ramsden (Ed.), Improving learning. New perspectives. (pp. 13-31). London: Kogan Page.

Ramsden, P. (1992). Learning to Teach in Higher Education. London: Routledge.

Trigwell, K., Prosser, M., \& Lyons, F. (1999). Relations between teachers' approaches to teaching and students' approaches to learning. Higher Education, 37, 57-70.

\section{Appendix 1}

Interview guide questions

1. What do the words "learning technologies" mean to you?

2. Can you give me an example of a learning technology.

3. What makes your example a learning technology and how would you use the learning technology in your teaching and how would students use your example in their learning?

4. What impact would your example have on your students learning? 


\section{Chris Cope and Peter Ward}

5. What do you mean by student learning or what do you attempt to achieve with your teaching?

6. The Government proposes that learning technologies bring about enhanced learning. What do you think the government means by enhanced learning? Is this the same as what you think enhanced learning is?

7. Do learning technologies bring about enhanced learning?

8. Do you think a digital camera is a learning technology? Why/why not? What about a normal camera?

9. When learning to draw an object in front of you a pencil and paper are normally used. Would you consider the pencil and paper to be a learning technology? Why/why not?

10. What about the WWW, a photocopier, a CD-Rom encyclopaedia? Are they learning technologies?

11. If two students of equal ability completed a work requirement and one used learning technologies and one didn't, would you expect students to have different learning outcomes from the completing the work requirements?

12. What is not a learning technology? Why is it not a learning technology?

13. What are the critical distinctions between learning technologies and non-learning technologies or learning non-technologies?

14. How has the professional development in Learning Technologies helped you this year?

\section{Biographies}

Chris Cope has been an IT academic for 15 years. Dr. Cope has completed a $\mathrm{PhD}$ and published a number of papers in IS and IT education.

Peter Ward has 25 years experience teaching IT and physics to high school students. His successful application for a financial grant from the Department of Education, Employment and Training led to the research reported in this paper. 